\title{
Population genetics of Polyphemus pediculus (Cladocera: Polyphemidae)
}

\author{
Lawrence J. Weider*
}

\begin{abstract}
Max-Planck-Institute for Limnology, Department of Ecophysiology, Postfach 165, D-2320 Plön, Federal Republic of Germany
\end{abstract}

Population genetic studies of cyclically parthenogenetic organisms have focussed on members of the freshwater cladoceran crustaceans, and mainly on those populations which inhabit intermittent or permanent ponds. Little is known of the genetic structure of large-lake populations.

The genetic structure of populations of the predatory freshwater littoral-zone cladoceran, Polyphemus pediculus from 20 palearctic lakes in Northern Germany was examined by electrophoresis to determine its breeding system and level of genetic polymorphism, and to compare its genetic structure with those of other Cladocera.

Polyphemus was polymorphic for three of eight enzyme loci and most (20/23) genotypic frequencies were in HardyWeinberg equilibrium. These populations are thus panmictic, and most likely reproduce by cyclical parthenogenesis. There were heterozygote deficiencies at each of the polymorphic loci in the three deviant populations. Genetic differentiation between populations was evident at each locus, with significant spatial autocorrelation found at the Pgm locus.

Population heterozygosity averaged 9.2 per cent with a mean of 1.5 alleles/locus. Mean number of composite genotypes per population was $6 \cdot 0+/-1 \cdot 0$ (S.E.) with a range of 1-17 clones per population. $P$. pediculus thus has a population genetic structure similar to that of large-lake Daphnia populations.

\section{INTRODUCTION}

Recent studies on the population genetic structure of cyclical parthenogens have concentrated on freshwater cladoceran crustaceans (Young, 1983). Most studies have examined populations that inhabit intermittent or permanent ponds (Hebert, 1974a, b; Lynch, 1983), and only recently have there been population genetic studies of large-lake cladocerans (Mort and Wolf, 1985, 1986; Wolf and Mort, 1986). Somewhat contrary to expectations (Lynch, 1983; Hebert, 1987), large lake Daphnia populations have a genetic structure quite similar to intermittent pond populations, as most populations are in Hardy-Weinberg (H.W.) equilibrium. However, unlike pond populations, there is little regional genetic divergence between populations. Interspecific hybridization (Wolf and Mort, 1986; Hebert et al., in preparation) may also be important in influencing the genetic structure of these largelake Daphnia populations.

\footnotetext{
* Address after 1 September, 1988: Great Lakes Institute, University of Windsor, Windsor, Ontario N9B 3P4 Canada.
}

Here I examine the genetic structure and breeding system of another member of the Cladocera, Family Polyphemidae. This taxon is represented in large freshwater lakes and in small ponds across North America and Euroasia by the single species, Polyphemus pediculus (L.) (Lilljeborg, 1901; Mordukhai-Boltovskoi, 1968). Zacharias (1906) and Strohl (1908) described the life-cycle and basic ecology of Polyphemus, and noted its predatory nature (feeding on microzooplankton), and unusual maternal secretion of nutritive fluid into the brood pouch containing the developing embryos. $P$. pediculus is a relatively small cladoceran; female adults range in size from 0.5 to $1.5 \mathrm{~mm}$ (Green, 1966).

The reproductive cycle is probably identical to that of other cyclically parthenogenetic cladocerans. Amictic females produce parthenogenetic broods during most of the year; male production and sexual (resting) egg formation generally occur in late autumn in north temperate lakes and ponds (Green, 1966). Polyphemus does not produce a resistant (ephippial) casing around its resting eggs (as do members of the 
Daphniidae), which might help in the dispersal of propagules by vectors such as water fowl. The resting eggs of Polyphemus (generally numbering between two and six eggs/brood; Green, 1966) usually fall to the lake sediments, or become attached to aquatic macrophytes. Dispersal of Polyphemus between habitats may thus be limited. Confirmation of the breeding system has never been directly examined in $P$. pediculus, and nothing is known of its population genetic structure.

\section{MATERIALS AND METHODS}

Polyphemus pediculus was found in 20 of 32 lakes (fig. 1) in Schleswig-Holstein (Federal Republic of Germany) during July and August 1987. It is primarily a littoral zone species (Hutchinson, 1967), and was collected in or near macrophyte stands by taking horizontal tows using a $250 \mu \mathrm{m}$ plankton net.

Individual females were assayed electrophoretically for allozyme phenotypes using cellulose acetate electrophoresis (Helena Scientific) following Hebert and Payne (1985), with modification of the methods of Harris and Hopkinson (1976). Four enzyme systems were assayed. Three were polymorphic: Pgm (phosphoglucomutase, PGM), $P g i$ (phosphoglucose isomerase, PGI), and $A o$ (aldehyde oxidase, $\mathrm{AO}$ ), while no variation in electrophoretic mobility was detected at Got (glutamate oxaloacetate transaminase, GOT). Several populations containing multiple genotypes (based on Pgm-Pgi-Ao electromorphs) were assayed at four additional loci ( Fum = fumarase, FUM; Hex = hexokinase, HEK; $M d h=$ malate dehydrogenase, $\mathrm{MDH} ; M p i=$ mannose phosphate isomerase, MPI), but no variation was detected at any of these loci.

Sample sizes ranged from 96-155 animals/ population. One population (No. 12; fig. 2) was surveyed at two sites to test for within-lake spatial heterogeneity (using G-tests of independence), and populations 4 and 12 (fig. 2) were surveyed at two to three week intervals from July to September to examine for temporal (seasonal) shifts in gene and genotype frequencies.

Standard H.W. tests and F-statistics ( $F_{s t}$; fixation index) were calculated following the methods outlined by Wright (1978), as well as between-population migration rate estimates using Wright's "island" model, which assumes equilibrium (Wright, 1978).

Spatial autocorrelation analysis (Cliff and Ord, 1981) was used to determine whether significant spatial patterning of allele frequencies and composite genotypes (based on Pgm-Pgi-Ao electromorphs) was present. Single autocorrelation coefficients (Moran's I) were calculated using the SAAP program (Wartenberg, 1985).

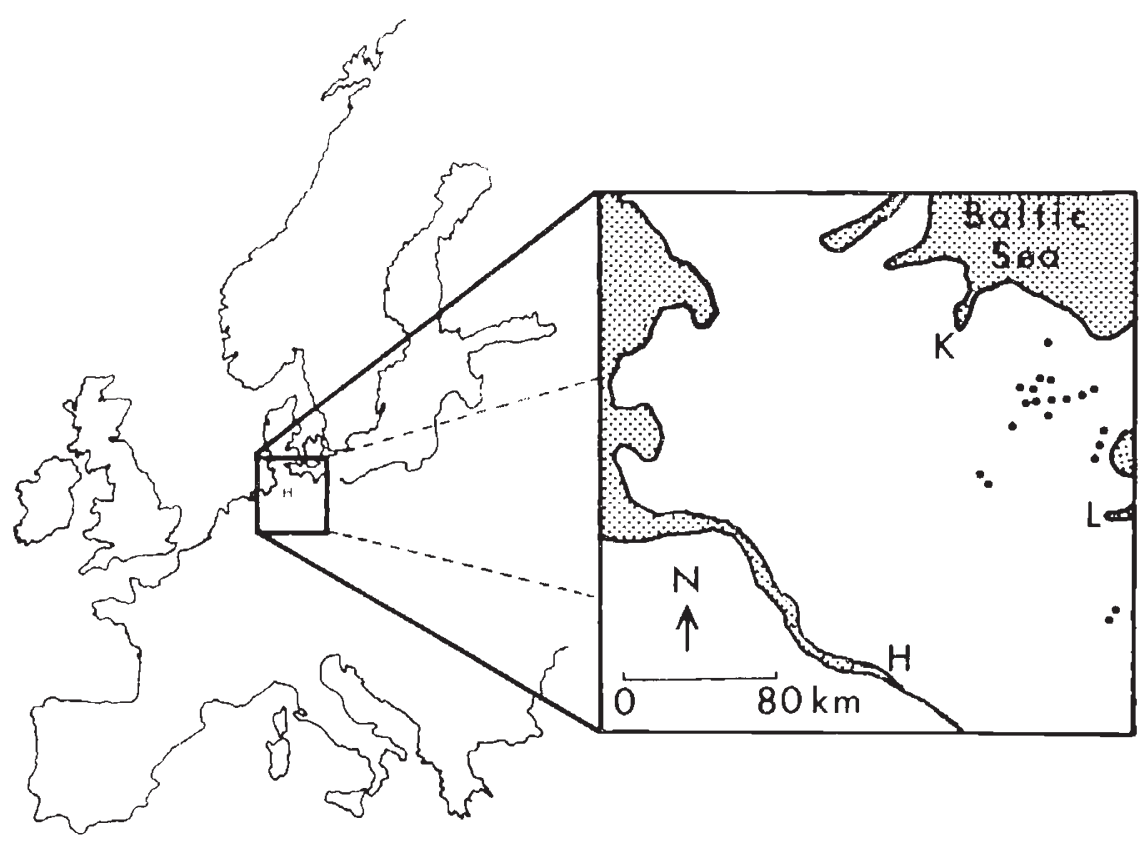

Figure 1 Location of Schleswig-Holstein, Federal Republic of Germany in Europe. Black dots represent the locations of the 20 lakes in which Polyphemus was found. $\mathrm{H}=\mathrm{Hamburg} ; \mathrm{K}=\mathrm{Kiel}$; $\mathrm{L}=$ Lübeck. 


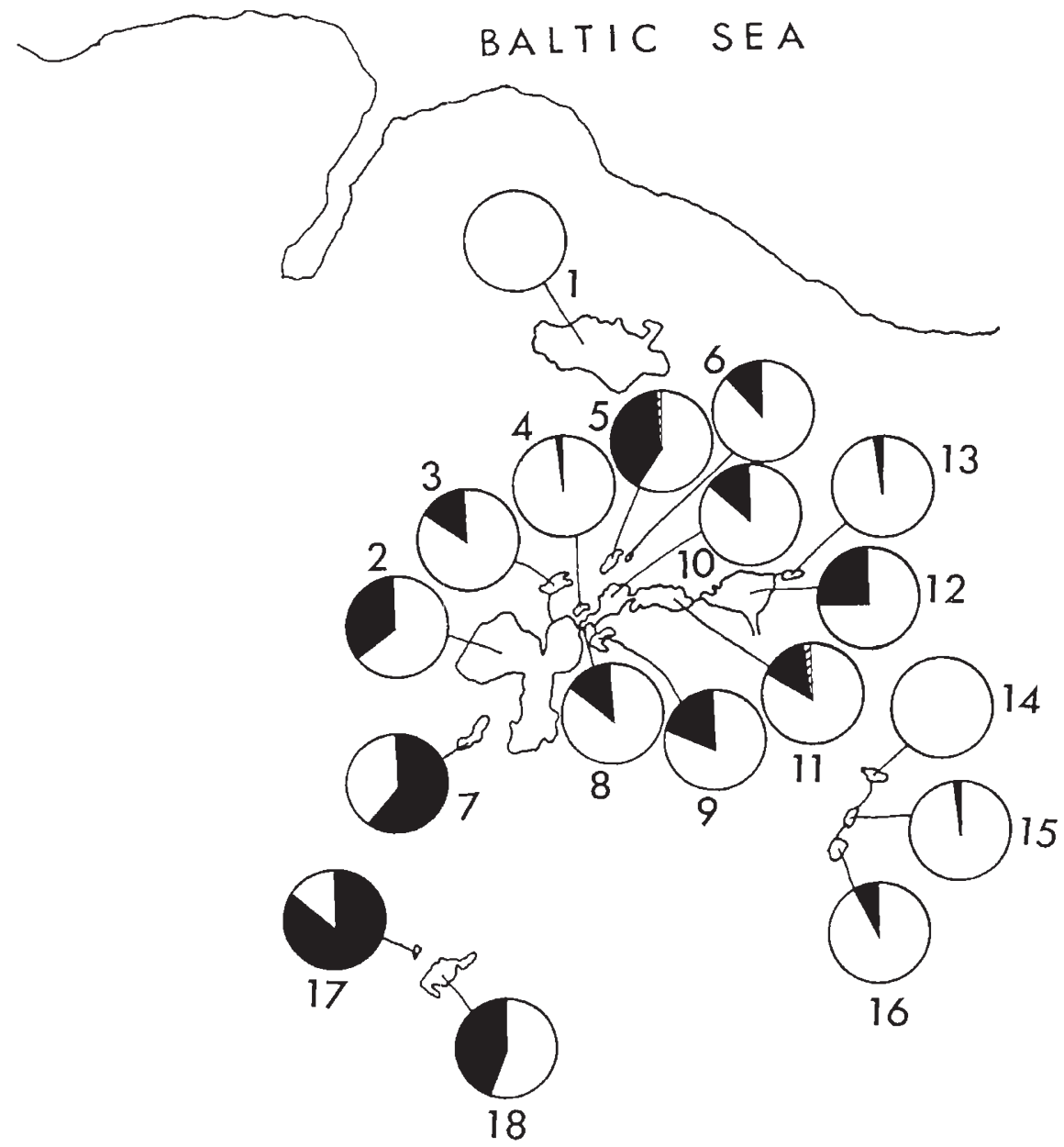

$N$

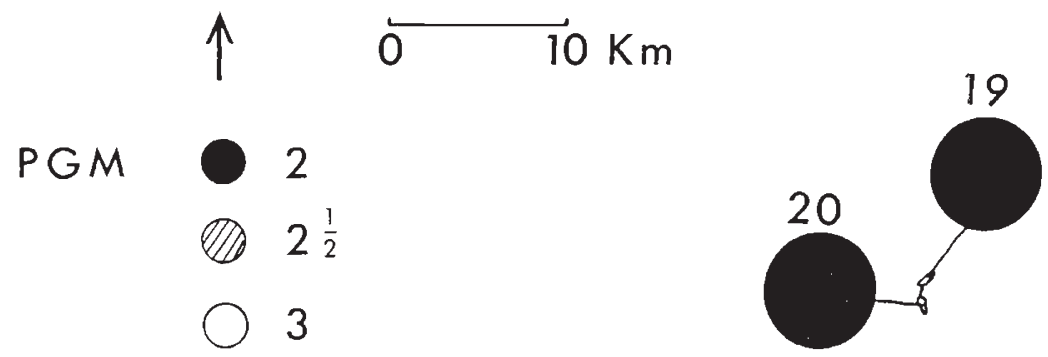

Figure 2 Pie diagrams depicting the allele frequencies of the 20 populations at the Pgm locus. See table 1 for population designations. The $2 \frac{1}{2}$ allele was detected in very low frequency only in populations 5 and 11 . The frequency of a given allele is proportional to the area of the pie covered by its symbol.

\section{RESULTS}

There were three alleles each at the Pgm and Pgi loci, and four alleles at the Ao locus (figs. 2, 3, and 4). Most genotype frequencies at these loci did not deviate significantly from $\mathrm{H}$.W. equilibrium
(20/23 comparisons in which the most common allele had a frequency of $<0.95$; table 1 ). There were exceptions for population No. 2 at the Pgm locus, population No. 3 at the Pgi locus, and population No. 10 at the Ao locus, where in all three cases, there were heterozygote deficiencies. 


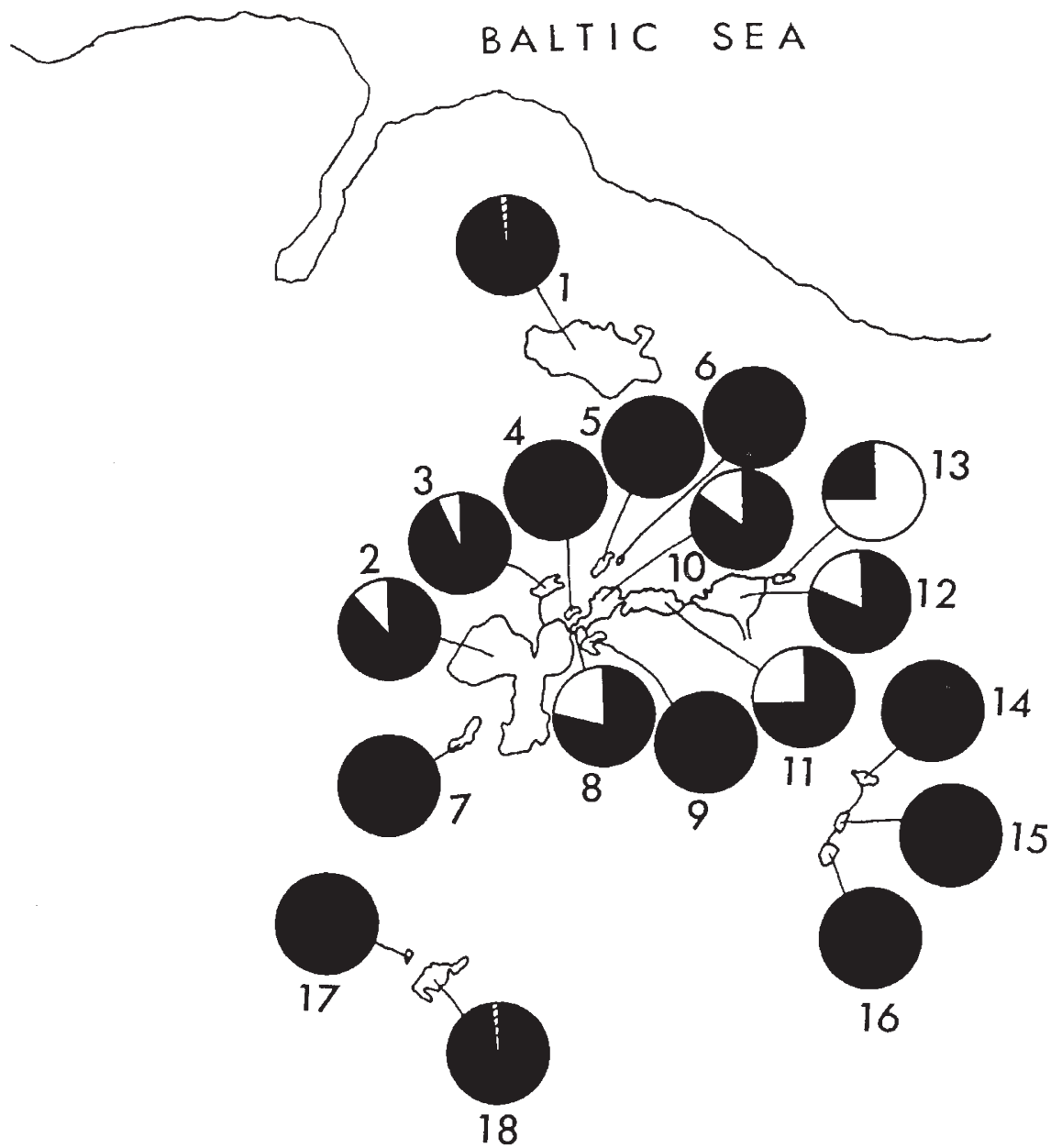

$N$
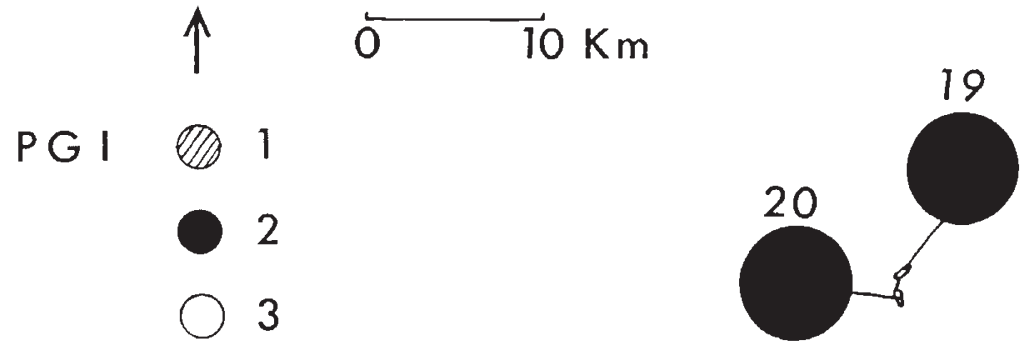

Figure 3 Pie diagrams depicting the allele frequencies of the 20 populations at the Pgi locus. The 1 allele was detected in very low frequency only in populations 1 and 18. See fig. 2 legend.

Geographical differences in allelic composition between populations were found at all three loci (figs. 2, 3, and 4). For example, the 2 allele at $\mathrm{Pgm}$ was at much lower frequency in populations located in the north and northeast of the study area (fig. 2). Further, the 3 allele at Pgi was restric- ted to populations, $2,3,8,10,11$, and 12 ; all of which are part of the Schwentine chain-of-lakes (fig. 3). All other populations lacked this allele, with the exception of population No. 13, which showed its highest frequency $(0.750)$. This lake flows into lake No. 12 via a small stream. For $A o$, 


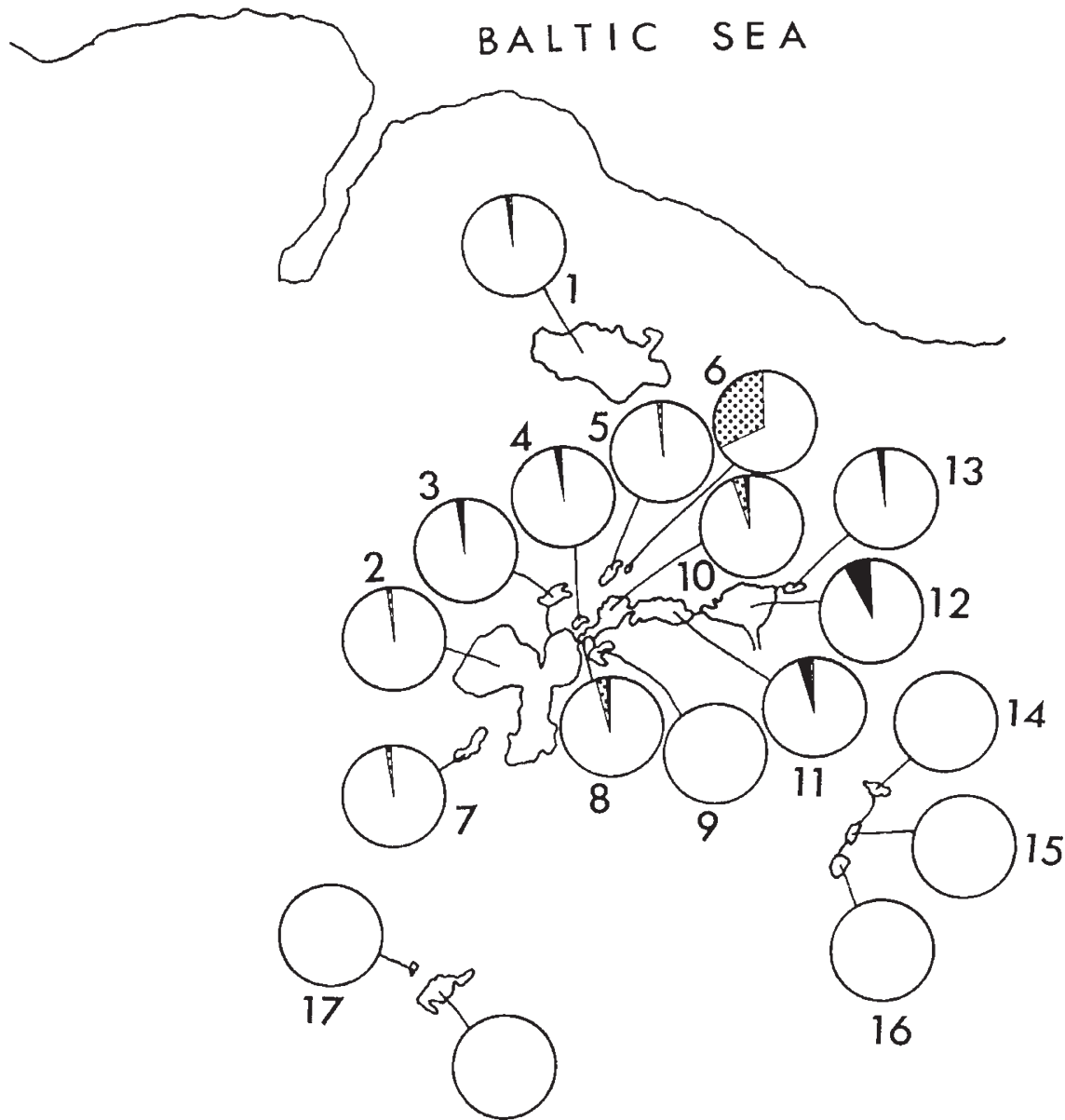

18

N
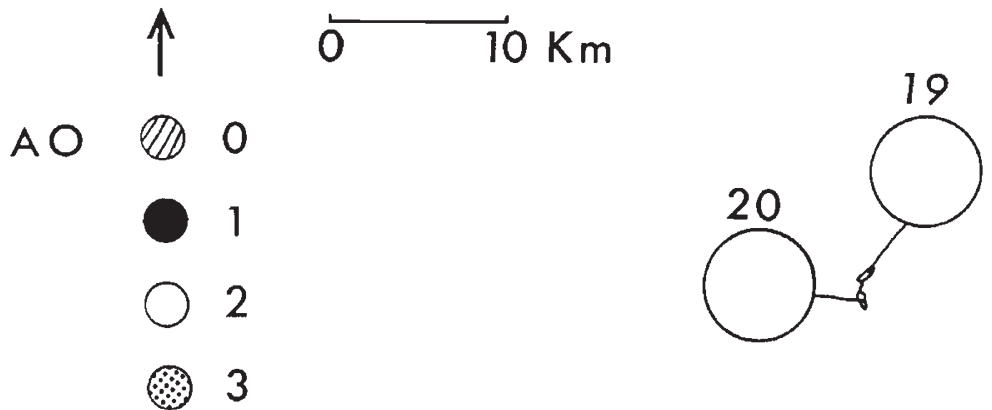

Figure 4 Pie diagrams showing allele frequencies of the 20 populations at the Ao locus. The 0 allele was detected only in population 1. See fig. 2 legend.

the 0 allele was in very low frequency only in population No. 1, while alleles 1 and 3 were found in low to moderate frequencies in many of the lakes located in the Schwentine watershed (fig. 4).

An examination of multi-locus genotypes (based on the Pgm-Pgi-Ao electromorphs; table 2; fig. 5) revealed an overall mean $(+/-$ S.E.) of $6 \cdot 0+/-1 \cdot 0$ genotypes/population (range 1-17; $N=20$ ). If one excludes the six Schwentine lakes (populations 2, 3, 8, 10, 11, and 12), the mean genotypic diversity decreases to $3 \cdot 6+/-0 \cdot 6$ 


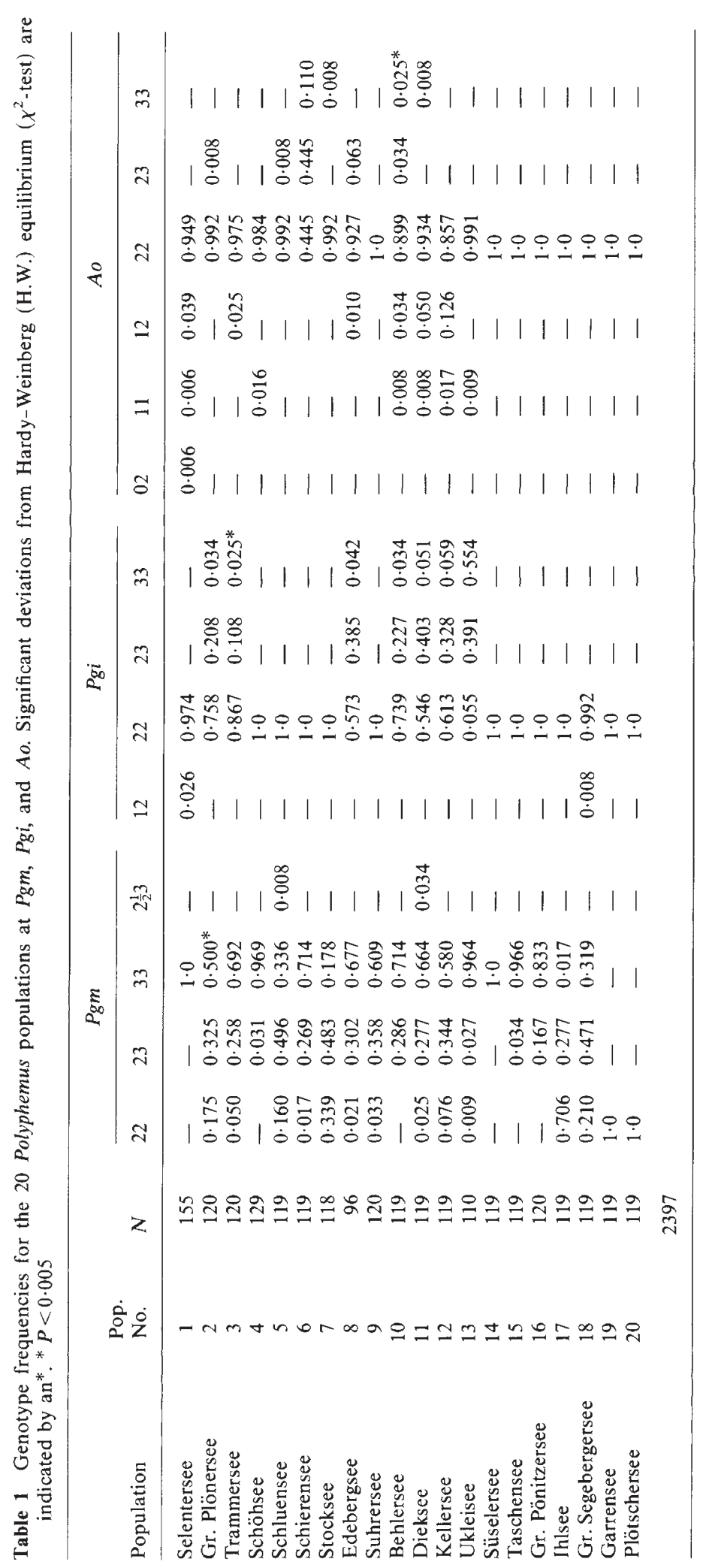


Table 2 Measures of genetic and genotypic variation within populations of Polyphemus pediculus. Numbers in parentheses (standard errors)

\begin{tabular}{|c|c|c|c|c|c|}
\hline Population & $\begin{array}{l}\text { Pop. } \\
\text { No. }\end{array}$ & $\mathrm{N}$ & $\begin{array}{l}\text { No. of } \\
\text { genotypes }\end{array}$ & $\begin{array}{l}\text { Mean No. of } \\
\text { alleles/locus }\end{array}$ & $\begin{array}{l}\text { Mean } \\
\text { heterozygosity }\end{array}$ \\
\hline Selentersee & 1 & 155 & 6 & $1 \cdot 7(0 \cdot 5)$ & $0.018(0.011)$ \\
\hline Gr. Plönersee & 2 & 120 & 9 & $1 \cdot 7(0 \cdot 2)$ & $0.135(0.079)$ \\
\hline Trammersee & 3 & 120 & 6 & $1 \cdot 7(0 \cdot 2)$ & $0.098(0.058)$ \\
\hline Schöhsee & 4 & 129 & 3 & $1 \cdot 2(0 \cdot 2)$ & $0.008(0.008)$ \\
\hline Schluensee & 5 & 119 & 5 & $1 \cdot 7(0 \cdot 5)$ & $0.128(0.125)$ \\
\hline Schierensee & 6 & 119 & 8 & $1.5(0 \cdot 3)$ & $0.179(0.109)$ \\
\hline Stocksee & 7 & 118 & 4 & $1 \cdot 5(0 \cdot 3)$ & $0 \cdot 121(0 \cdot 121)$ \\
\hline Edebergsee & 8 & 96 & 12 & $2 \cdot 0(0 \cdot 4)$ & $0.190(0.091)$ \\
\hline Suhrersee & 9 & 120 & 3 & $1 \cdot 7(0 \cdot 5)$ & $0.090(0.090)$ \\
\hline Behlersee & 10 & 119 & 12 & $2 \cdot 0(0.4)$ & $0.145(0.067)$ \\
\hline Dieksee & 11 & 119 & 14 & $2 \cdot 2(0 \cdot 5)$ & $0.191(0.098)$ \\
\hline Kellersee & 12 & 119 & 17 & $1.7(0.2)$ & $0.200(0.083)$ \\
\hline Ukleisee & 13 & 110 & 7 & $1.7(0.2)$ & $0.104(0.096)$ \\
\hline Süselersee & 14 & 119 & 1 & $1 \cdot 0(0 \cdot 0)$ & $0.0 \quad(0.0)$ \\
\hline Taschensee & 15 & 119 & 2 & $1 \cdot 2(0 \cdot 2)$ & $0.008(0.008)$ \\
\hline Gr. Pönitzersee & 16 & 120 & 2 & $1 \cdot 2(0 \cdot 2)$ & $0.042(0.042)$ \\
\hline Ihlsee & 17 & 119 & 3 & $1 \cdot 2(0 \cdot 2)$ & $0.069(0.069)$ \\
\hline Gr. Segebergersee & 18 & 119 & 4 & $1 \cdot 5(0 \cdot 3)$ & $0.120(0.117)$ \\
\hline Garrensee & 19 & 119 & 1 & $1 \cdot 0(0 \cdot 0)$ & $0.0 \quad(0.0)$ \\
\hline \multirow[t]{2}{*}{ Plötschersee } & 20 & 119 & 1 & $1.0(0 \cdot 0)$ & $0.0 \quad(0.0)$ \\
\hline & & & $\bar{X}=6 \cdot 0(1.0)$ & $1 \cdot 5(0 \cdot 1)$ & $0.092(0.016)$ \\
\hline
\end{tabular}

genotypes/population (range 1-8). The six Schwentine lakes averaged $11 \cdot 6+/-1 \cdot 6$ genotypes/population (range 6-17). Only population No. 6 (table 2) showed a significant $(P<0.005)$ deviation from expected numbers of three-locus genotypes, assuming zygotic phase equilibrium (Mort and Wolf, 1986). Including monomorphic loci, the mean number of alleles per locus was $1 \cdot 5+/-0 \cdot 1$ (S.E.), and overall mean heterozygosity for populations was $0.092+/-$ $0 \cdot 016$ (S.E.; table 2).

Significant spatial autocorrelation was detected only at the Pgm locus for the 2 and 3 alleles (both $I$ values equalled $+0 \cdot 001 ; P<0 \cdot 001)$. Of the three most common genotypes (fig. 5), only genotype 3 showed significant spatial autocorrelation, which was positive $(I=+0 \cdot 009 ; P<0 \cdot 00002)$, and thus indicated that adjacent (or nearby) populations are more similar to each other than populations located farther apart. This implies a nonrandom distribution for genotype 3 .

No significant within-lake temporal or spatial changes in genotypic frequencies were found (table $3)$. Genetic differentiation among all populations (table 4) as measured by $F_{s t}$ values ranged from $0 \cdot 157-0 \cdot 463$. The six Schwentine populations (No. $2,3,8,10,11$, and 12) showed greatly reduced levels of genetic differentiation with values ranging from $0 \cdot 015-0 \cdot 027$ (table 4 ). A migration rate of about $0 \cdot 5$ migrants/generation (table 4 ) was estimated between all populations using the island model (Wright, 1978). For only those lakes outside the Schwentine system, the estimate was about $0 \cdot 3$ migrants/generation, while the estimate for the six Schwentine populations was 11.7 migrants/generation.

Table 3 Results of $G$-tests of independence $(R \times C)$ for temporal and spatial genotype frequency changes in populations 4 (Schöhsee) and 12 (Kellersee) during late summer 1987

\begin{tabular}{lllllll}
\hline Population & Locus* & Alleles & Analysis & df & $G$ & $P$ \\
\hline 4 & $P g m$ & $2 \cdot 3$ & Temporal & 2 & $4 \cdot 18$ & $\mathrm{~ns}$ \\
12 & $P g m$ & $2 \cdot 3$ & Temporal & 4 & $1 \cdot 23$ & $\mathrm{~ns}$ \\
& $P g m$ & $2 \cdot 3$ & Spatial & 2 & $0 \cdot 82$ & $\mathrm{~ns}$ \\
& $P g i$ & $2 \cdot 3$ & Temporal & 4 & $1 \cdot 02$ & $\mathrm{~ns}$ \\
& $P g i$ & $2 \cdot 3$ & Spatial & 2 & $5 \cdot 03$ & $\mathrm{~ns}$ \\
\hline
\end{tabular}

* Ao was not analyzed because of insufficient sample sizes for the rarer alleles 0,1 , and 3 . 

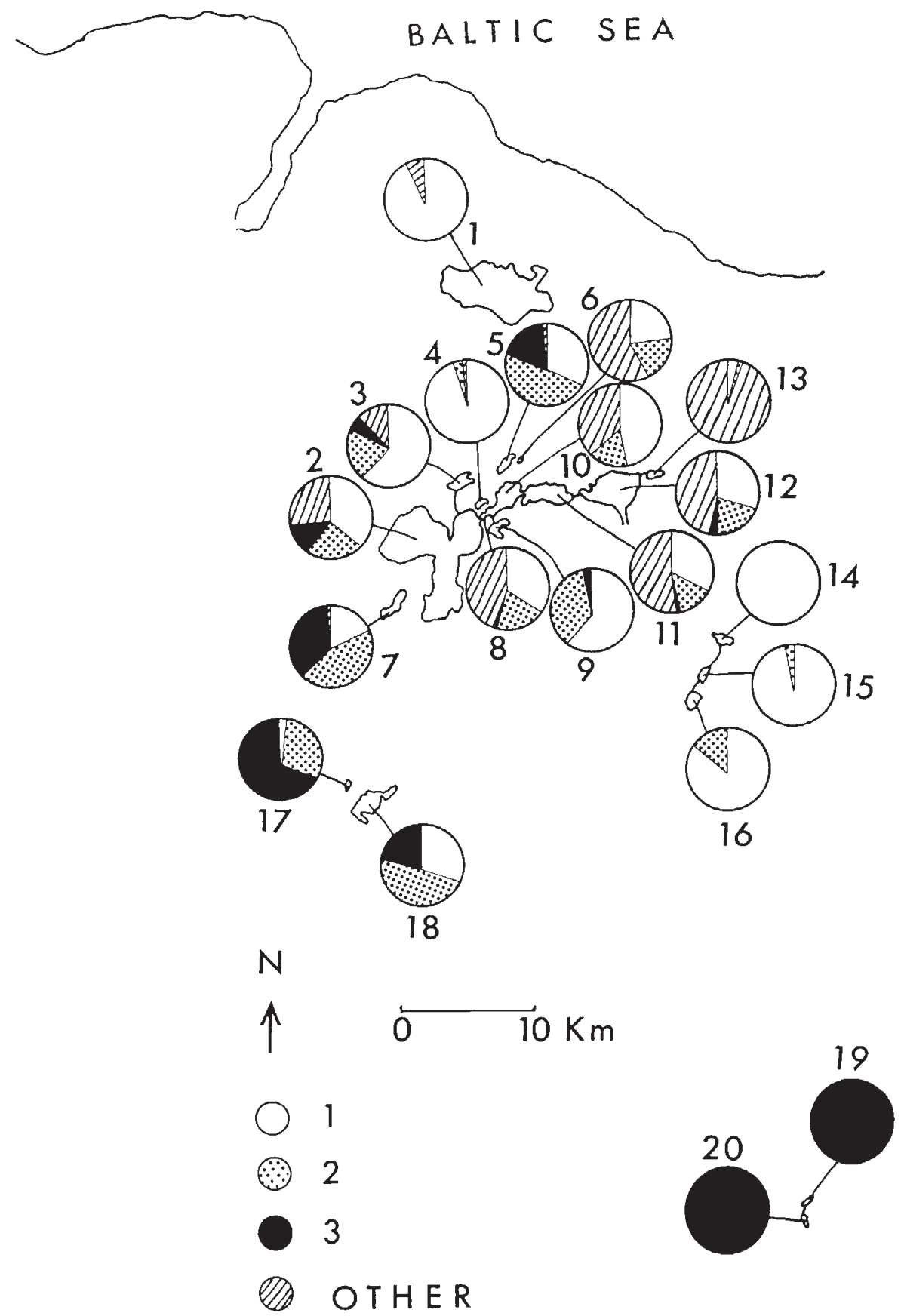

Figure 5 Pie diagrams showing the distributions and proportions of the three most common composite genotypes in each of the 20 populations. The frequency of a given genotype is proportional to the area of the pie covered by its symbol. Genotype designations based on Pgm-Pgi-Ao electromorphs are: genotype 1 33-22-22; genotype 2 23-22-22; and genotype $322-22-22$.

\section{DISCUSSION}

Polyphemus pediculus populations are characterized by genotypic frequencies in H.W. equilibrium, which are temporally and spatially quite "stable" within lakes. This implies that large-lake Polyphemus populations are reproducing by cyclical parthenogenesis, as its structure approximates that of a truly sexual species, and resembles that of large-lake Daphnia populations (Mort and Wolf, 
Table $4 F$-statistics ( $F_{s t}$ values) representing levels of genetic differentiation at each of the three polymorphic loci between Polyphemus populations, both within and outside the Schwentine chain-of-lakes, and estimates of migration rates ( $N_{m}$-number of migrants/generation) based on the "island" model (Wright, 1978)

\begin{tabular}{lllll}
\hline Populations & Locus & $\mathrm{N}$ & $\mathrm{F}_{\text {st }}$ value & $\begin{array}{l}\text { Mean } \\
N_{m^{*}}\end{array}$ \\
\hline All & Pgm & 20 & 0.463 & 0.51 \\
& Pgi & 20 & 0.364 & \\
& Ao & 20 & 0.157 & \\
& & & $X=0.328$ &
\end{tabular}

Excludes

Schwentine

lakes

$\begin{array}{llr}\text { Pgi } & 14 & 0.720 \\ \text { Pgm } & 14 & 0.591 \\ \text { Ao } & 14 & 0.163 \\ & & X=0.491\end{array}$

$0 \cdot 26$

$X=0 \cdot 491$

$\begin{array}{lllr}\begin{array}{l}\text { Only } \\ \text { Schwentine }\end{array} & & & \\ \text { lakes } & P g i & 6 & 0.027 \\ & P g m & 6 & 0.021 \\ & \text { Ao } & 6 & 0.015 \\ & & & X=0.021\end{array}$

${ }^{*} N_{m}=1 /(4 F)-0 \cdot 25$

1986), as well as intermittent pond populations (Hebert, 1987).

There was genetic differentiation among populations, particularly in those outside the Schwentine chain-of-lakes. Among the six Schwentine populations, genetic differentiation was low, and the genotypic diversity high (mean of 11.6 genotypes/population, compared to a mean for all other populations of 3.6 genotypes/population). Within-population genotypic diversity was quite variable with a range of 1-17 genotypes per population. The relatively high genotypic diversity in the Schwentine populations may be a result of mixing of stocks from various source populations that flow into this system. For example, allele 3 at $P g i$ (fig. 3) was only found in the Schwentine populations, except for population No. 13, which had a high frequency of this $P G I-3$ allele, and which is connected to the Schwentine system via a stream.

Migration rate estimates are variable among populations (table 4). For example, active dispersal of migrants via connecting channels in the Schwentine lake system may be reflected in its low levels of genetic differentiation $\left(F_{s t}\right.$ values ranged from $0.015-0.027)$ and relatively high migration rate (approximately 11.7 migrants/generation; table 4). This migration rate estimate may be conservative based on the "island" model (Wright,
1978); an one-dimensional "stepping-stone" model may be more appropriate (Slatkin, 1985).

Hebert (1987) concludes that the dispersal capabilities of cladocerans (principally daphniids) are far more limited than previously believed with an average migration rate between-populations of less than $1 \mathrm{migrant} /$ generation. Excluding the Schwentine populations, migration rate estimates for Polyphemus pediculus averaged between $0 \cdot 3$ and 0.5 migrants/generation, and are therefore comparable to other cladocerans (Hebert, 1987). This is somewhat surprising, since Polyphemus lacks an ephippial casing for its latent eggs, which might increase passive dispersal between habitats (Proctor, 1964).

Spatial autocorrelation analysis revealed significant spatial patterning of allele frequencies for only the Pgm locus, while only genotype 3 (fig. 5) showed a nonrandom spatial distribution. Historical factors such as founder effect may be important in influencing the spatial patterning of allele and genotype frequencies, especially in some of the more isolated populations, but selection might also be involved. Composite genotypes (clones) of obligately parthenogenetic Daphnia are not ecological equivalents (see Hebert, 1987), so that fitness components vary among clones (Hebert, 1974a; Lynch, 1983, 1984; Weider, 1987). However, Lynch (1984) showed that while there are clonal differences within cyclically parthenogenetic Daphnia populations, these average out at the composite genotype level. It is difficult to maintain Polyphemus in the laboratory (personal abservation), so potential fitness differences between Polyphemus genotypes remain untested.

Polyphemus pediculus (L.) is the sole representative of the Family Polyphemidae in freshwater habitats (Lilljeborg, 1901; MordukhaiBoltovskoi, 1968). Lynch (1985) suggests that speciation in the Cladocera may occur via founder effect if the source population of colonizers is a year-round resident of large, permanent lakes and rarely engages in sex; the founder population colonizes a site which is small, ephemeral and/or distant from the source; the colonizing propagules lack an efficient transport mechanism and carry few eggs; and selection on founders is intense prior to the first sexual phase. Polyphemus does not meet these criteria since sexual reproduction is not rare and gene flow (among north German populations) seems sufficient to impede genetic divergence. A more detailed discussion of possible speciation events in $P$. pediculus is beyond the scope of this present study; future research is warranted. 
Acknowledgements I thank H. G. Wolf for critical assistance in the field and stimulating discussions, M. Lynch and an anonymous reviewer for valuable comments on an earlier version of the manuscript, E. Geissler for lab assistance, and W. Lampert for encouragement and support. Finally, I thank the Max-Planck-Gesellschaft, Federal Republic of Germany for Postdoctoral Fellowship support.

\section{REFERENCES}

ClifF, A. D. AND ORD, J. K. 1981. Spatial Processes: Models and Applications, Pion, London.

GREEN, J. 1966. Seasonal variation in egg production by Cladocera. J. Anim. Ecol., 35, 77-104.

HARRIS, H. AND HOPKINSON, D. A. 1976. Handbook of Enzyme Electrophoresis in Human Genetics, American Elsevier, New York.

HEBERT, P. D. N. 1974a. Enzyme variability in natural populations of Daphnia magna. 1I. Genotypic frequencies in permanent populations. Genetics, 77, 323-334.

HEBERT, P. D. N. 1974 b. Enzyme variability in natural populations of Daphnia magna. III. Genotypic frequencies in intermittent populations. Genetics, 77, 335-341.

HEBERT, P. D. N. 1987. Genotypic characteristics of the Cladocera. Hydrobiologia, 145, 183-193.

HEBERT, P. D. N. AND PAYNE, W. J. 1985. Genetic variation in populations of the hermaphroditic flatworm Mesostoma lingua (Turbellaria; Rhabdocoela). Biol. Bull., 169, 143151.

Hutchinson, G. E. 1967. A Treatise on Limnology, vol. 2, Wiley, New York, U.S.A.

LilljebOrG, w. 1901. Cladocera Sueciae. Nova Acta Reg. Soc. Sci. Upsal., 19, 1-701.

LYNCH, M. 1983. Ecological genetics of Daphnia pulex. Evolution, 37, 358-374.
LYNCH, M. 1984. The genetic structure of a cyclical parthenogen. Evolution, 38, 186-203.

LYNCH, M. 1985. Speciation in the Cladocera. Verh. Internat. Verein. Limnol, 22, 3116-3123.

MORDUKHAI-BOLTOVSKOI, PH. D. 1968. On the taxonomy of the Polyphemidae. Crustaceana, 14, 197-209.

MORT, M. A. AND WOLF, H. G. 1985. Enzyme variability in large-lake Daphnia populations. Heredity, 55, 27-36.

MORT, M. A. AND WOLF, H. G. 1986. The genetic structure of large-lake Daphnia populations. Evolution, 40, 756-766.

PROCTOR, V. W. 1964. Viability of crustacean eggs recovered from ducks. Ecology, 45, 656-658.

Slatkin, M. 1985. Gene flow in natural populations. Ann. Rev. Ecol. Syst., 16, 393-430.

STroht, J. 1908. Die Biologie von Polyphemus pediculus und die Generationszyklen der Cladoceren. Zool. Anzeiger, 32, $19-25$.

WARTENBERG, D. E. 1985. Spatial autocorrelation analysis program (SAAP), SAAP User's Guide Version 2.3 (unpublished).

WEIDER, L. J. 1987. Life history variation among low-Arctic clones of obligately parthenogenetic Daphnia pulex: a diploid-polyploid complex. Oecologia, 73, 251-256.

WOLF, H. G. AND MORT, M. A. 1986. Interspecific hybridization underlies phenotypic variability in Daphnia populations. Oecologia, 68, 507-511.

WRIGHT, S. 1978. Evolution and The Genetics of Populations. vol. 4., Variability Within and Among Natural Populations, Univ. Chicago Press, Chicago, U.S.A., 580pp.

YOUNG, J. P. W. 1983. The population structure of cyclic parthenogens. In Oxford, G. S. and D. Rollinson (eds) Protein Polymorphism: Adaptive and Taxonomic Significance, Syst. Assoc. Spec., vol. 24, Academic Press, New York, pp. 361-378.

ZACHARIAS, O. 1906. Zur Biologie und Ökologie von Polyphemus pediculus (Linne). Zool. Anzeiger, 30, 455-459. 